\title{
Elevated collagen-I augments tumor progressive signals, intravasation and metastasis of prolactin-induced estrogen receptor alpha positive mammary tumor cells
}

Craig E. Barcus ${ }^{1,2}$, Kathleen A. O'Leary ${ }^{2}$, Jennifer L. Brockman², Debra E. Rugowski ${ }^{2}$, Yuming Liu ${ }^{5}$, Nancy Garcia ${ }^{2}$, Menggang $Y u^{4,6}$, Patricia J. Keely ${ }^{1,3,5,6}$, Kevin W. Eliceiri ${ }^{5,6}$ and Linda A. Schuler ${ }^{1,2,6^{*}}$

\begin{abstract}
Background: The development and progression of estrogen receptor alpha positive (ERa+) breast cancer has been linked epidemiologically to prolactin. However, activation of the canonical mediator of prolactin, STAT5, is associated with more differentiated cancers and better prognoses. We have reported that density/stiffness of the extracellular matrix potently modulates the repertoire of prolactin signals in human ERa + breast cancer cells in vitro: stiff matrices shift the balance from the Janus kinase (JAK)2/STAT5 cascade toward pro-tumor progressive extracellular regulated kinase (ERK)1/2 signals, driving invasion. However, the consequences for behavior of ERa + cancers in vivo are not known.

Methods: In order to investigate the importance of matrix density/stiffness in progression of ERa + cancers, we examined tumor development and progression following orthotopic transplantation of two clonal green fluorescent protein (GFP) + ERa + tumor cell lines derived from prolactin-induced tumors to 8-week-old wild-type FVB/N (WT) or collagen-dense

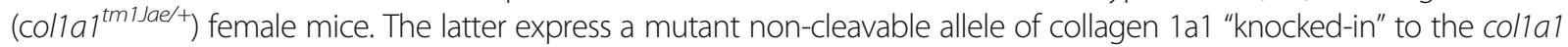
gene locus, permitting COL1A1 accumulation. We evaluated the effect of the collagen environment on tumor progression by examining circulating tumor cells and lung metastases, activated signaling pathways by immunohistochemistry analysis and immunoblotting, and collagen structure by second harmonic generation microscopy.

Results: ERa + primary tumors did not differ in growth rate, histologic type, ERa, or prolactin receptor (PRLR) expression between colla $1^{\text {tm IJae/+ }}$ and WT recipients. However, the colla $1^{\text {tm IJae/+ }}$ environment significantly increased circulating tumor cells and the number and size of lung metastases at end stage. Tumors in colla ${ }^{\text {tm } 1 \mathrm{Jae} / \mathrm{t}}$ recipients displayed reduced STAT5 activation, and higher phosphorylation of ERK1/2 and AKT. Moreover, intratumoral collagen fibers in coll ${ }^{\text {tm }}{ }^{1 / \mathrm{Ja} / \mathrm{t}}$ recipients were aligned with tumor projections into the adjacent fat pad, perpendicular to the bulk of the tumor, in contrast to the collagen fibers wrapped around the more uniformly expansive tumors in WT recipients.
\end{abstract}

Conclusions: A collagen-dense extracellular matrix can potently interact with hormonal signals to drive metastasis of ERa + breast cancers.

Keywords: Tumor microenvironment, Collagen, Desmoplasia, Breast cancer, Extracellular matrix, Tumor progression, Prolactin

\footnotetext{
*Correspondence: linda.schuler@wisc.edu

${ }^{1}$ Cellular and Molecular Biology Program, University of Wisconsin-Madison,

Madison, WI, USA

${ }^{2}$ Department of Comparative Biosciences, University of Wisconsin-Madison,

Madison, WI, USA

Full list of author information is available at the end of the article
} 


\section{Background}

Metastatic estrogen receptor $\alpha$ positive $(\mathrm{ER} \alpha+)$ breast cancer is the leading cause of breast cancer mortality [1-3]. However, the mechanisms that drive progression of these cancers are poorly understood, in part because there are few animal models of ER $\alpha+$ breast cancer. The extracellular matrix (ECM) is increasingly recognized as an important contributor to tumor behavior. Aggressive tumors frequently display desmoplasia, one component of which is increased deposition of fibrillar collagens such as collagen-I [4-6]. This increased matrix deposition frequently increases the stiffness of the tumor and adjacent tissue [7]. Stiff ECM environments drive tumorprogressive characteristics both in vitro [8] and in mouse models [9-11]. Moreover, tumors can actively remodel the surrounding ECM. Aligned collagen-I fibers increase ECM stiffness [12], and collagen fibers aligned perpendicularly to the boundary of larger tumors predict poor outcomes, particularly of ER $\alpha+$ cancers [13]. Collagen-I density/stiffness increases pro-tumorigenic signaling cascades in tumor epithelia, such as focal adhesion kinase (FAK), src family kinases (SFKs), and extracellular regulated kinase (ERK)1/2 [14]. The effects of these changes on hormonal signals and consequences for their roles in the progression of ER $\alpha+$ tumors are not well-understood.

Large prospective epidemiologic studies have linked the hormone, prolactin (PRL), to increased risk of development of aggressive ER $\alpha+$ cancers, and smaller-scale studies also suggest that it contributes to their progression [15-18]. However, activation of STAT5, the primary physiological effector of prolactin (PRL), is associated with favorable clinical outcomes [19-21], and reduces invasion of breast cancer cells in vitro [22, 23]. Interestingly, FAK, SFKs, and ERK1/2 are also activated by PRL [24-26], and the ability of PRL to activate STAT5 is inversely related to its ability to activate AP-1 via mitogen-activated protein (MAP) kinases and augment invasiveness [27]. We recently reported that collagen-I density/stiffness is a major determinant of the signaling pathways that are available to the PRL receptor (PRLR). Whereas $\mathrm{ER} \alpha+$ breast cancer cells cultured in low density/compliant three-dimensional collagen I matrices respond to PRL predominantly by activating physiological JAK2/STAT5 signals, high density/stiff matrices shift PRL responses to pathological ERK1/2 signals and increase invasiveness [28]. Under these latter conditions, PRL crosstalk with estrogen increases alignment of the matrix perpendicular to the tumor edge [29], similar to that correlated with decreased survival of patients with $\mathrm{ER} \alpha+$ tumors $[13,30]$. These data indicate that PRL and the ECM cooperate to drive processes leading to progression of breast cancer. However, examination of this interplay in vivo is necessary to confirm its importance and investigate clinical applications.
In order to examine the interaction between PRL and increased collagen-I deposition in an immunocompetent environment in vivo, we took advantage of wellcharacterized genetically modified mouse models. Hormonally responsive mouse models of breast cancer are rare [31, 32]. The neu-related lipocalin-prolactin (NRLPRL) transgenic mouse mimics the local PRL synthesis in the mammary glands of women. Nulliparous female mice spontaneously develop aggressive mammary tumors, about $75 \%$ of which are ER $\alpha+$ [33]. ER $\alpha+$ tumor cell lines derived from these adenocarcinomas are readily transplantable to syngeneic recipients [34]. To model increased collagen I, we utilized the Colla1 ${ }^{\text {tmJae1 }}$ mouse [35]. Mutation of the MT1-MMP cleavage site in Col1a1 reduces collagen-I turnover, leading to its accumulation, without a need for additional fibrotic factors and any associated confounding activities. We have previously shown that this increases metastasis from experimental MMTV-PyMT-induced mammary tumors, and results in a collagen fiber signature that predicts poor survival in patients with breast cancer $[13,14,36]$.

Here, we orthotopically transplanted clonal green fluorescent protein (GFP)-labeled PRL-induced ER $\alpha+$ mammary tumor cell lines into syngeneic wild-type (WT) or heterozygous mutant collagen-I female mice (Col1a1 $1^{\text {tmJae/+ }}$ mCol1a1). Tumors that developed in the mColla1 environment had similar rates of growth, morphology, ER $\alpha$, and PRLR expression to those in the WT collagen environment. However, the mColla1 environment increased circulating tumor cells (CTCs), and the number and size of lung metastases. It also altered the pattern of activated signaling cascades in the primary tumors: tumors in mColla1 female mice had lower pSTAT5 and increased pERK1/2 and pAKT expression, consistent with predictions from in vitro studies. Moreover, the alignment of intratumoral collagen fibers near the tumor boundary in mColla1 recipients was more perpendicular to the tumor edge and oriented in parallel to protrusions invading into the adjacent fat pad. These data indicate that extracellular matrix can potently interact with hormonal signals to drive the development of metastasis from $\mathrm{ER} \alpha+$ breast cancers.

\section{Methods}

Reagents

Antibodies used in these studies were purchased from the following vendors: ERK1/2 (\#9102), pERK1/2 (\#9101), AKT (\#9272), pAKT S473 (\#9271), pAKT S473 (\#3787S, for immunohistochemical analysis) from Cell Signaling Technology (Danvers, MA, USA); pSTAT5 (\#71-6900) from Invitrogen (Grand Island, NY, USA); ER $\alpha$ (\#sc-542), PRLR (\#sc-20992), STAT5 (\#sc-835x) from Santa Cruz Biotechnology (Santa Cruz, CA, USA); eGFP (\#AB6658) from AbCam (Cambridge, MA, USA); 
PR (\#A0098) from Dako (Carpinteria, CA, USA); biotinylated goat anti-rabbit (\#BA-100) from Vector Labs (Burlingame, CA, USA); pan-actin (\#125-ACT) from Phosphosolutions (Aurora, CO, USA); APCconjugated CD31 (\#551262) and CD45 (\#559864) from BD Biosystems (San Jose, CA, USA). Avidin-biotin complex (ABC) (\#PK-4000) and ImmPACT DAB (\#SK4105) were purchased from Vector Labs (Burlingame, CA, USA). All other reagents were obtained from Fisher Scientific or Sigma-Aldrich.

\section{Cell lines and culture}

$\mathrm{ER} \alpha+$ mouse mammary tumor cell lines were derived from a NRL-PRL mammary tumor [34, 37]. Two independently derived cell lines were stably transfected with eGFP, TC2GR12 (TC2) and TC4GR5 (TC4), and clonal sublines were maintained on tissue culture plastic in Roswell Park Memorial Institute medium (RPMI) 1640 supplemented with $10 \%$ FBS, $1 \%$ penicillin/streptomycin, and $1 \mathrm{mg} / \mathrm{ml}$ (TC2GR12) or $400 \mu \mathrm{g} / \mathrm{ml}$ (TC4GR5) puromycin as a selection factor. As shown in Additional file 1, TC2GR12 (TC2) and TC4GR5 (TC4) both express the rPRL transgene and exhibit somewhat differing levels of hormone receptor and signal effector proteins.

\section{Animals}

Mice heterozygous for Colla1 ${ }^{\text {tmJae }}$ [35] (Colla1 ${ }^{\text {tmJae/+}}$; mCol1a1) were backcrossed onto the FVB/N strain background for 10 generations. Mice were housed and cared for in accordance with the Guide for Care and Use of Laboratory Animals in AAALAC-accredited facilities. All procedures were approved by the University of Wisconsin-Madison Animal Care and Use Committee. For some experiments, $2.5 \times 10^{4}$ (TC2GR12) or $7.5 \times 10^{4}$ (TC4GR5) cells in $50 \mu \mathrm{l}$ of sterile PBS were orthotopically injected into the left caudal mammary fat pads of 8 to 10week-old FVB/N WT or mColla1 female mice and allowed to progress to end stage (tumor $1.5 \mathrm{~cm}$ in diameter). All recipients survived to end stage. For analysis of early-stage tumors, cell lines were injected bilaterally into the caudal mammary fat pads of 8 to 10 -week-old WT or heterozygous mColla1 female mice, and tumors were allowed to progress for 17 days (TC2) or 24 days (TC4), the time of peak CTCs, respectively, before collection. Each animal was palpated biweekly to assess tumor development, and tumor diameter was measured using electronic calipers. Tumor volume was calculated as the largest diameter * (smallest diameter $\left.{ }^{2}\right) * 0.4$.

\section{Flow cytometry}

Peripheral blood $(100 \mu \mathrm{l})$ was collected from each animal weekly from a maxillary vein in $6 \mathrm{U}$ heparin sulphate, starting 3 days after tumor cell transplantation. Red blood cells were lysed in $0.15 \mathrm{M} \mathrm{NH}_{4} \mathrm{Cl}+1.2 \mathrm{mM}$ EDTA for 10 minutes with gentle agitation. Cleared blood was centrifuged at $300 \times \mathrm{g}$ for 5 minutes, washed in PBS, and stained with anti-CD31/APC (1:100) and anti-CD45/ APC (1:100) for 30 minutes on ice to label hematopoietic cells. The labeled cell suspension was then washed, fixed in $2 \%$ paraformaldehyde, and analyzed for endogenous GFP and CD31/45+ hematopoietic cells on a BD Fortessa flow cytometer, using the gating strategy presented in Additional file 2. Seven blood samples from non-injected female mice (five WT, two mCol1a1) served as controls for each experiment, and average background auto-fluorescence was subtracted from the experimental results.

\section{Immunohistochemical analysis and immunofluorescence}

Immunohistochemical analyses were performed as previously described [38]. Briefly, tissues were fixed in $10 \%$ neutral buffered formalin, embedded in paraffin, and serial-sectioned. Deparaffinized tissues were hydrated in decreasing concentrations of ethyl alcohol $(\mathrm{EtOH})$ and endogenous peroxidase activity quenched in $3 \% \mathrm{H}_{2} \mathrm{O}_{2}$ in methanol $(\mathrm{MeOH})$. Dilutions of the primary antibodies, antigen retrieval, and blocking conditions are shown in Additional file 3. Secondary antibody (1:250) and signal amplification (avidin-biotin complex $(\mathrm{ABC})$ ) were performed at room temperature prior to chromogen-detection with ImmPACT 3,3-diaminobenzidine (DAB) according to the manufacturer's instructions. Tissues were counterstained with hematoxylin, dehydrated, and mounted for microscopic analysis. For immunofluorescence experiments, tissues were processed as described without performing peroxidase quenching. Alexa-488 conjugated streptavidin (1:100) was incubated at room temperature for $1 \mathrm{~h}$ prior to mounting with anti-fade media and subsequent epifluorescence imaging.

\section{Lung metastasis analysis}

All animals were allowed to progress to end stage (tumor diameter $1.5 \mathrm{~cm}$ ). At this time, lungs were collected and fixed in $10 \%$ neutral buffered formalin. After $24 \mathrm{~h}$, surface nodules on all lung lobes were counted under a dissection microscope. The left lobe was then sectioned in four step-sections of $50 \mu \mathrm{m}$ with two serial sections at each step. GFP immunofluorescence was performed as described to assess micrometastatic load. Total numbers of GFP+ lesions were counted per $\times 10$ field of view (FOV) over seven FOVs per lung. The area of each lesion was calculated and the total sum of lesion area determined per FOV. Three independent lungs were analyzed for each cell line/genotype combination over two 50- $\mu \mathrm{m}$ steps, using Image [39]. 


\section{Immunoblotting}

Snap-frozen tumor pieces were homogenized in ice cold $40 \mathrm{mM}$ Tris, $276 \mathrm{mM} \mathrm{NaCl}, 20 \%$ glycerol, 2\% NP-40, $4 \mathrm{mM}$ EDTA, $20 \mathrm{mM} \mathrm{NaF}, 2 \mathrm{mM}$ sodium orthovanadate, $40 \mu \mathrm{g} / \mathrm{ml}$ phenylmethane sulfonylfluoride (PMSF), and $50 \mu \mathrm{g} / \mathrm{ml}$ aprotinin. Briefly, $30 \mu \mathrm{g}$ of tumor homogenate was fractionated by SDS-PAGE, transferred to polyvinylidene fluoride (PVDF) membranes, and then probed with appropriate antibodies (ERK1/2, 1:2000; pERK1/2, 1:5000; STAT5, 1:50000; pSTAT5, 1:1000; E R $\alpha, 1: 1000 ;$ AKT, 1:2000; pAKT S473, 1:1000; PRLR, $1: 1000)$. Signals were visualized by enhanced chemiluminescence and quantified by densitometry (UVP Visionworks). All end-stage tumors were analyzed.

\section{Collagen imaging and analysis}

Paraffin-embedded, 5- $\mu \mathrm{m}$ sections of early lesions were stained with picrosirius red as previously described [40]. Polarized light microscopy with $\mathrm{a} \times 10$ objective was utilized to assess birefringence that is specific to fibrillar collagens. Multiphoton microscopy and second harmonic generation (SHG) imaging were performed as previously described [41]. Briefly, collagen was visualized with a laser excitation of $890 \mathrm{~nm}$ with a $445 \pm 20 \mathrm{~nm}$ emission filter to detect backwards SHG focused on the sample with $a \times 20 / 0.75 \mathrm{NA}$ objective. The overall fiber alignment analysis was performed with the CurveAlign software following fiber detection utilizing CT-FIRE $[42,43]$. The alignment coefficient was based on the orientation of the collagen fibers in the same image and ranges from 0 to 1 , where the larger the alignment coefficient, the more aligned the fibers.

\section{Statistical analysis}

Statistical analyses were performed in GraphPad Prism v4.0 or SAS/STAT v9.4. Data were tested for normality using the Shaprio-Wilk test. Data were analyzed using the unpaired $t$ tests (normal data) or Mann-Whitney $U$ non-parametric test (non-normal data) as indicated. Tumor growth and CTC data were analyzed using two-way repeated measures analysis of variance (ANOVA), taking into account values across days in the same animals. Collagen alignment was quantified using repeated measure group comparison with the SAS Proc Mixed model to take into account image-image and tumortumor variation for each cell line/genotype combination. Significance of the data are presented as $* p<0.05, * *<$ $0.01, * * * 0.001$, or $* * * * * 0.0001$.

\section{Results}

Increasing collagen-I does not alter primary tumor growth, yet increases circulating tumor cells

In order to study the effect of a collagen-dense environment on progression of PRL-induced ER $\alpha+$ mammary cancer, we orthotopically transplanted GFP+ TC2 or TC4 tumor cells into WT or mColla1 female mice and monitored growth until end stage. Increased collagen-I did not alter the growth of either TC2 or TC4 tumors (Fig. 1a-b). In order to assess the mobilization of tumor epithelia into the bloodstream as an indicator of metastatic potential, peripheral blood was collected weekly from the maxillary vein and analyzed for circulating GFP + tumor cells (CTCs) as described in "Methods". In mCol1a1 recipients of both TC2 and TC4 cells, CTCs were significantly higher than in WT recipients (Fig. 1b, TC2, $p<0.0050$; TC4, $p<0.0320)$. Interestingly, levels of CTCs peaked considerably prior to end stage (TC2, day 17; TC4, day 31 after transplantation).

\section{Collagen-I does not change tumor histology or hormone receptor status}

Transplantation of both TC2 and TC4 cell lines resulted in spindle cell carcinomas in both WT and mCol1a1 recipients (Fig. 2a). As expected, tumors in mColla1 animals showed increased Masson's trichrome staining near the tumor boundary compared to those in WT mice, reflecting increased connective tissue in this mutated environment (Fig. 2b). Like the parent cell lines, TC tumors were also $\mathrm{ER} \alpha+$, and collagen deposition did not alter ER $\alpha$ expression discerned by either immunohistochemical (Fig. 2c) or western analyses (Fig. 2d). PRLR expression in these tumors was not altered by collagen accumulation (Additional file 4A); progesterone receptor (PR) was expressed in localized foci (Additional file 4B).

\section{Metastasis of ERa + mammary tumors is enhanced by increasing collagen-I}

$\mathrm{ER} \alpha+$ breast cancers metastasize to multiple peripheral tissues, including the lungs [44]. As the mColla1 background increased CTCs (Fig. 1b), we collected the lungs at end stage to determine the consequences for metastasis to this site. Significantly more surface lung nodules were found in mCol1a1 recipients of both TC2 and TC4 cells (Fig. 3a, b; Additional file 5). Histologic examination revealed that mColla1 female mice bearing either TC2 or TC4 tumors also had higher numbers of metastatic lesions in the lung parenchyma (Fig. 3c, d) $(p<0.0001)$, visualized utilizing GFP as a marker (Fig. 3j, k, n, o). Moreover, these lesions were significantly larger (Fig. 3e, f) $(p<0.01)$, resulting in a greatly increased total metastatic burden in mCol1a1 mice (Fig. 3g, h) $(p<0.0001)$.

mCol1a1 decreases pSTAT5, and increases pERK1/2 and pAKT in ERa + mammary tumors

We have previously shown that characteristics of the collagen ECM alter the spectrum of PRL-induced signals with behavioral consequences in human breast cancer 

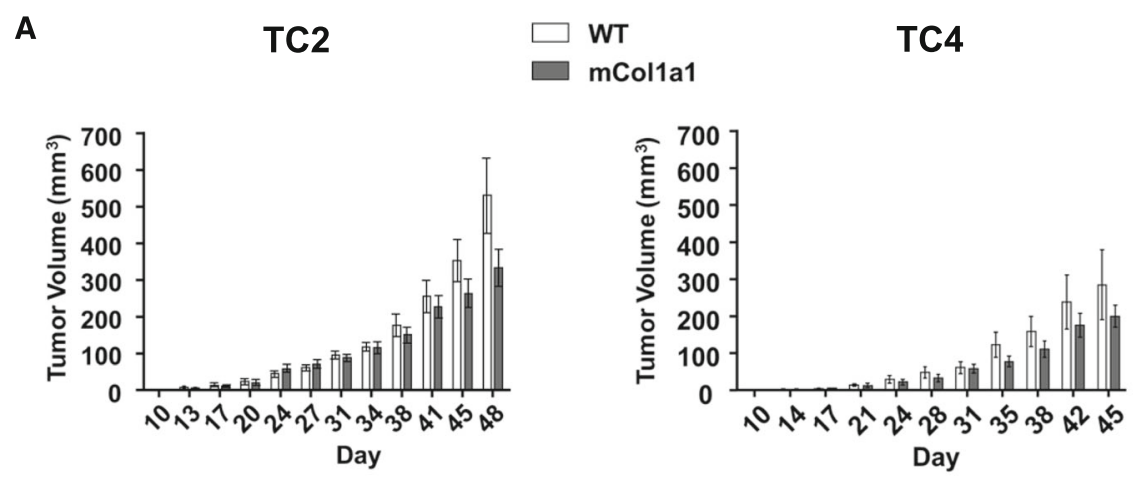

B
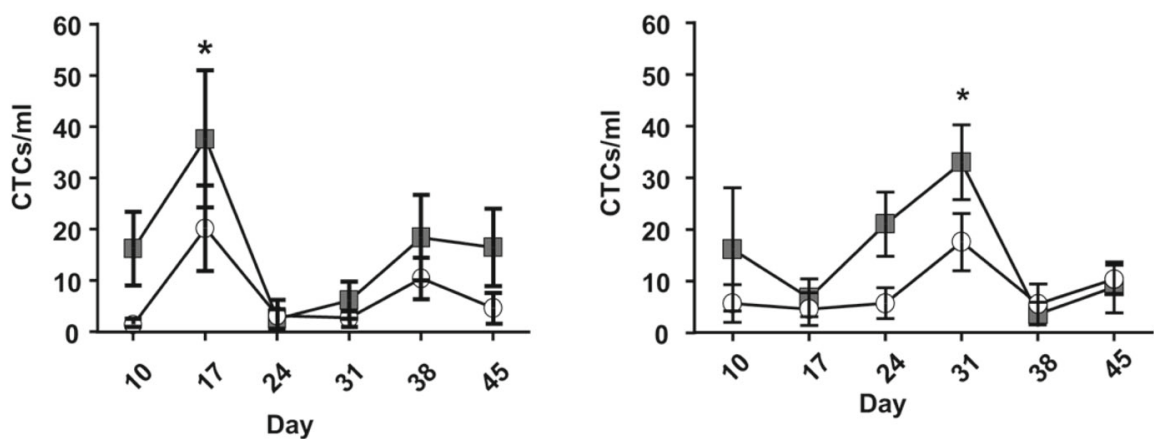

Fig. 1 mCol1a1 does not alter the rate of tumor growth, but increases circulating tumor cells. a-b Tumor growth of tumor cell line (TC)2 (a) and TC4 (b) tumors until collection of the largest tumors began. Tumor volume was measured biweekly. Mean \pm SEM TC2 animals: wild-type (WT) $n=7$, mCol1a1 $n=6$. TC4 animals: WT $n=7$, mCol1a1 $n=8$. Time significantly influenced tumor volume in both TC2 (a) and TC4 (b) tumors $(p<0.0001$, two-way repeated measures ANOVA), but genotype did not. c-d Circulating tumor cells (CTCS) in peripheral blood of animals bearing TC2 (c) or TC4 (d) tumors. Peripheral blood was collected weekly and analyzed for green fluorescent protein positive (GFP+) CTCS as described in "Methods". Mean \pm SEM TC2 recipients: WT $n=7$, mCol1a1 $n=6$. TC4 recipients: WT $n=7$, mCol1a1 $n=8$. Genotype significantly altered levels of CTCs (TC2, $p<0.0050$; TC4, $p<0.0320$; repeated measure two-way ANOVA, taking into account values across days in the same animals). Levels of CTCs peaked when tumors were relatively small, regardless of genotype (TC2, day 17 is significantly different from all other days except day 38 , ${ }^{*} p<0.05$; TC4, day 31 is significantly higher than day 17 and day $38,{ }^{*} p<0.05$ )

cells in vitro: stiff/dense matrices reduce signals to STAT5, while increasing signals through ERK1/2 [28, 29]. While high pSTAT5 is associated with increased differentiation and lower proliferation [19-21], signals through ERK1/2 increase proliferation of breast cancer cells and may contribute to tumor progression [14, 45].

Activation of AKT is associated with metastatic ER $\alpha+$ breast cancer, and the efficacy of anti-estrogens in combination with therapies targeting this pathway are currently under clinical evaluation [46, 47]. To determine if the high collagen-I environment in vivo alters these signaling cascades, we performed immunoblotting and immunohistochemical analyses. Tumors that grew from both cell lines in mColla1 recipients had lower pSTAT5 $(p<0.05$, Fig. $4 \mathrm{a}, \mathrm{d})$, similar to human breast cancer cells cultured in dense/stiff matrices in vitro. TC2 tumors had higher pERK1/2 in mColla1 female mice, compared to WT recipients $(p<0.05$, Fig. $4 \mathrm{~b})$, while TC4 tumors trended similarly $(p=0.11$, Fig. 4 e). Similarly, relative levels of pAKT were significantly higher in tumors from both cell lines $(p<0.05$, Fig. $4 \mathrm{c}, \mathrm{f})$. These results were confirmed by immunohistochemical analysis, with lower nuclear pSTAT5 staining in tumors in mColla1 compared to WT recipients (Fig. 4g) (Additional file 6A), and higher nuclear and cytoplasmic pERK1/2 and pAKT in mCol1a1 female mice bearing TC2 (Fig. 4h, i) and TC4 (Additional file 6B, C) tumors.

\section{Early tumors in mCol1a1 recipients exhibit finger-like protrusions containing aligned collagen fibers}

At end stage, tumors nearly fill the mammary fat pads. In order to examine the characteristics of the tumor boundaries, we examined lesions earlier after transplantation, at the time when CTCs were elevated, particularly in $\mathrm{mCol1a} 1$ recipients (day $17, \mathrm{TC} 2$ or day 24, TC4; Fig. 1b). Early-stage tumors in both WT and mColla1 recipients exhibited the spindle cell morphology evident at end stage (Fig. 5a). However, the tumor boundaries were quite different in the two host genotypes. Whereas both TC2 and TC4 tumors in WT recipients displayed a generally uniform pattern of expansion, lesions in mColla1 hosts exhibited many vascular finger-like protrusions into the surrounding mammary fat pads (Fig. 5b, c). Picrosirius red staining with polarized light 


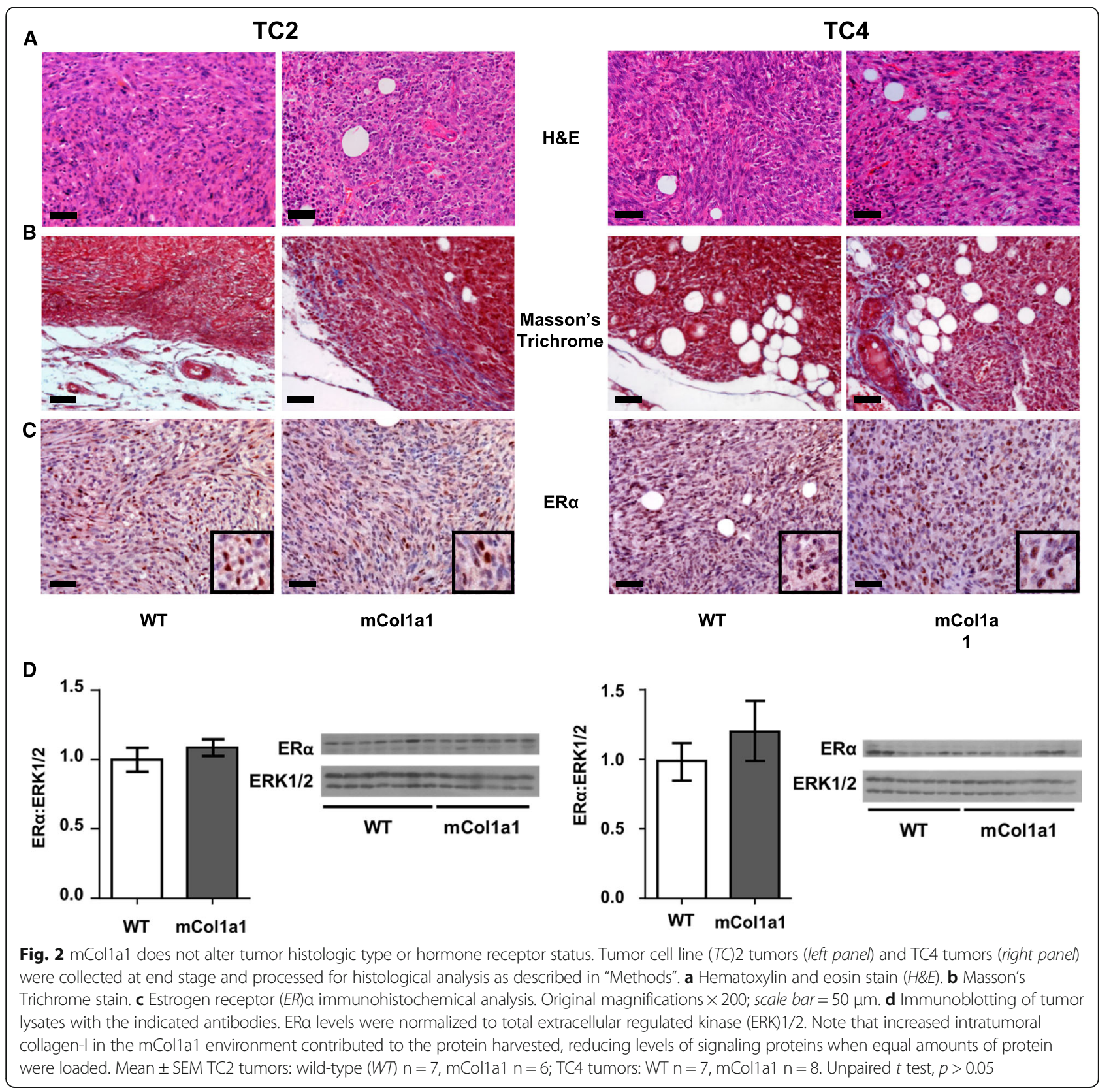

microscopy revealed dense collagen fibers that were aligned with the tumor projections in mColla1 recipients, while fibers in tumors in WT animals were wrapped around the tumor edge (Fig. 5d), similar to collagen fibers observed in non-aggressive tumors $[13,48]$. SHG microscopy in combination with analysis of the alignment of collagen fibers showed that collagen fibers in tumors of WT recipients aligned with one another parallel to the tumor edge, while those in tumors of mColla1 recipients were less consistently oriented (Fig. 5e, f) $(p<0.0001, \mathrm{TC} 2 ; p<0.05, \mathrm{TC} 4)$, with many perpendicular to the bulk of the tumor and/or aligned with the protrusions into the fat pad.

\section{Discussion}

Metastasis of ER $\alpha+$ breast cancer is poorly understood. ECM characteristics such as alignment of the collagen fibers in and around the tumor correlate with poor survival [13], demonstrating the importance of this component of the tumor microenvironment. However, the role of hormones in these events, and the consequences of changes in the ECM for hormone actions have not been clear. While some evidence supports a role for elevated PRL exposure in tumor progression [18], conflicting data on PRL-induced signal effectors suggest that other factors modulate PRL responses. We previously demonstrated in vitro that a dense/stiff 


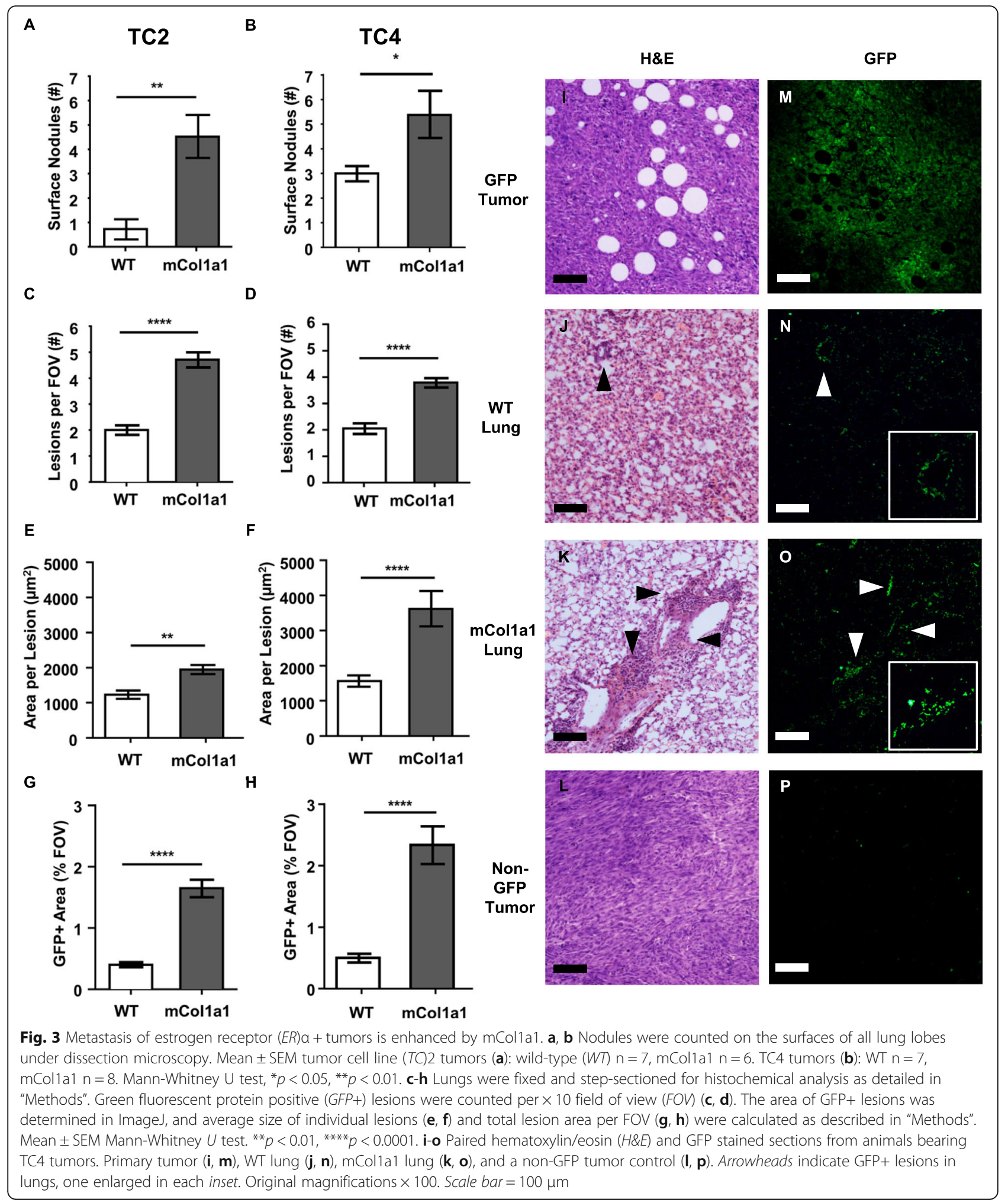

collagen-I matrix shifts the balance of PRL signals from physiological to tumor progressive, and permits PRL and estrogen to reorient collagen-I fibers that mimic aggressive $E R \alpha+$ breast cancers in women $[28,29]$. Here, we report that the predictions from these studies are confirmed in an immunocompetent mouse model in vivo: collagen-I accumulation promoted ERK $1 / 2$ and AKT activation and decreased STAT5 phosphorylation in PRL- 


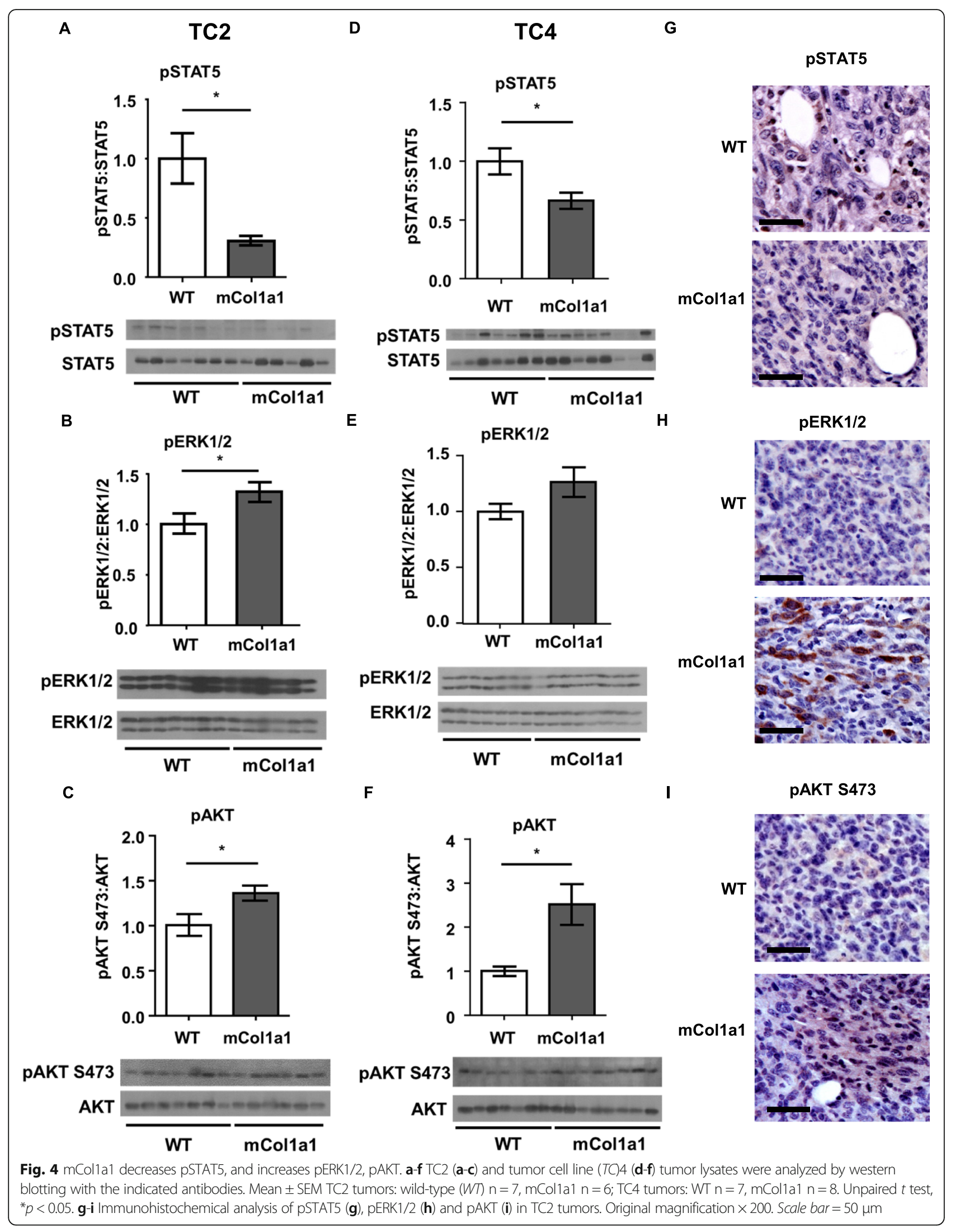


TC2
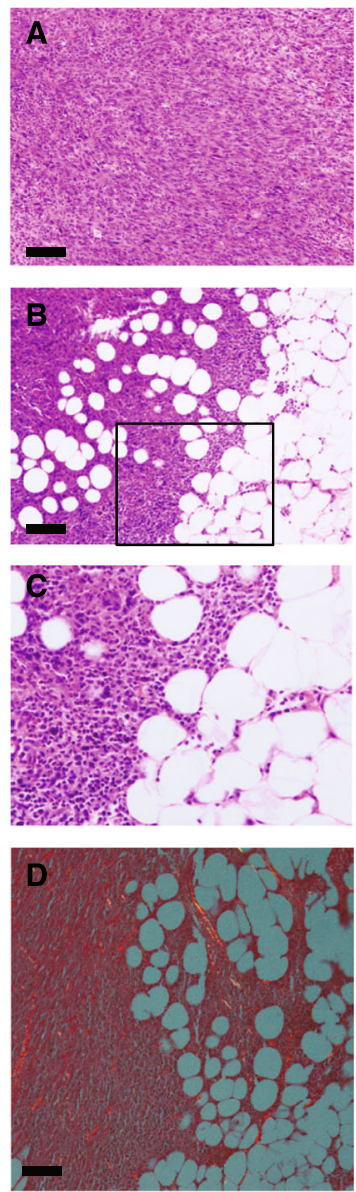

TC4
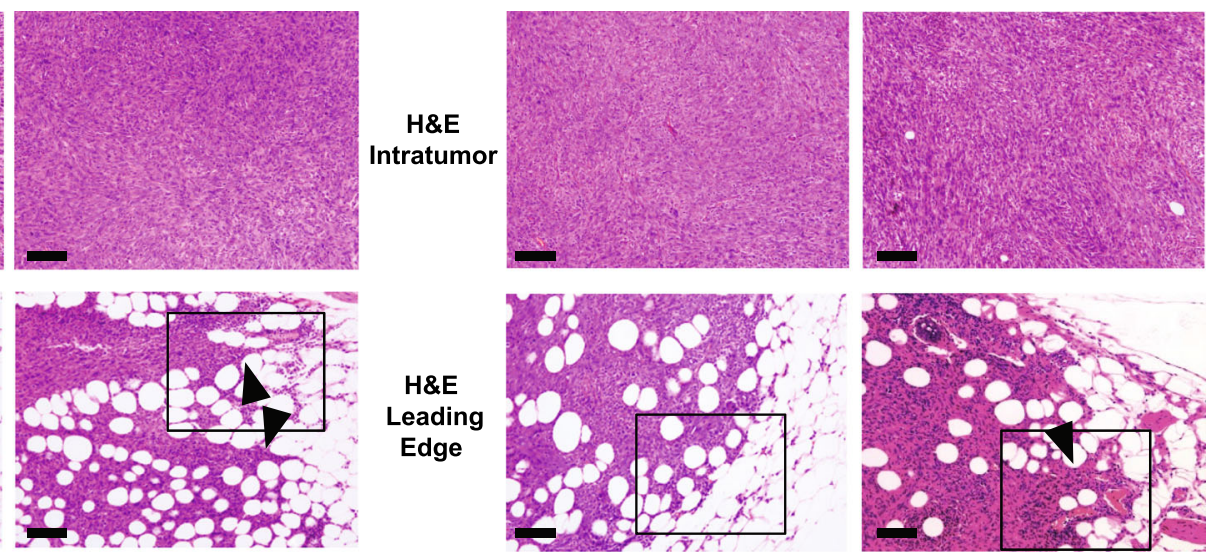

H\&E

Leading

Edge
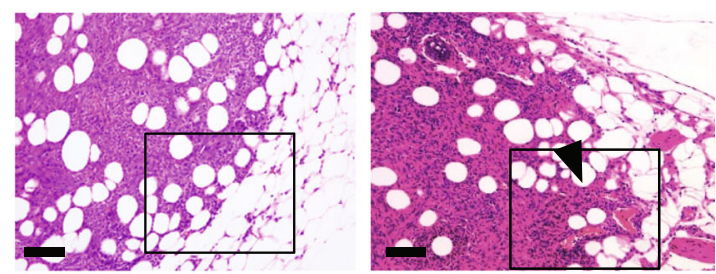

H\&E

Leading

Edge
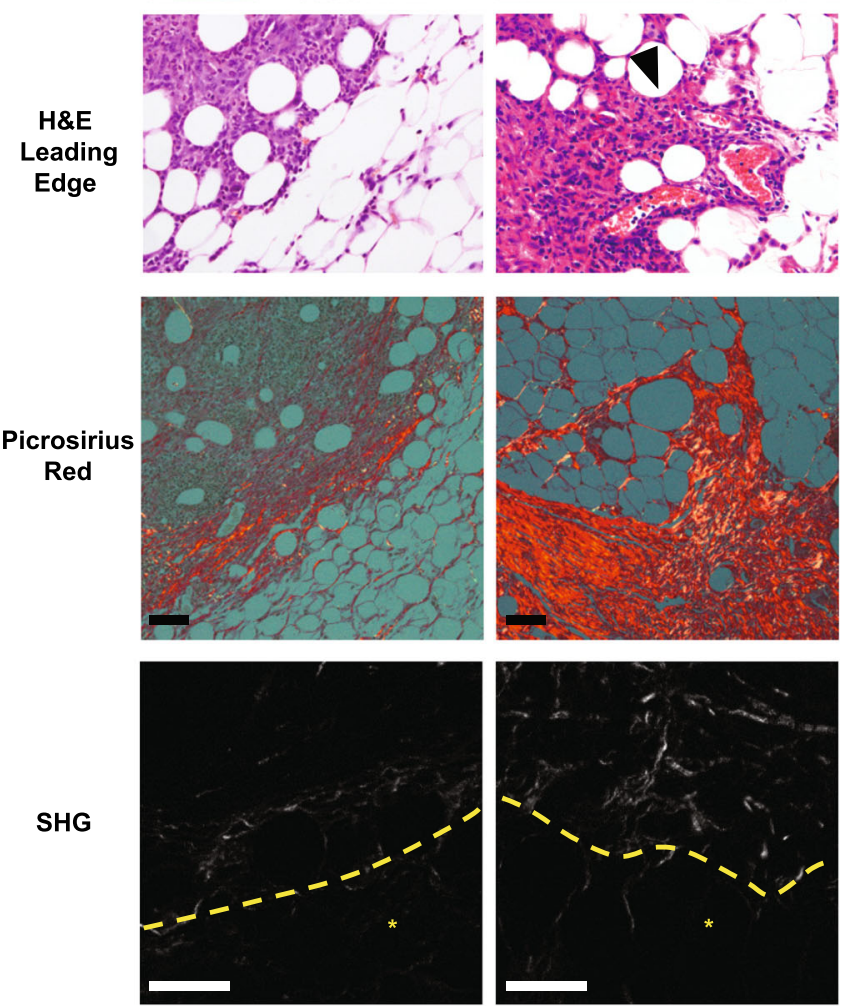

WT

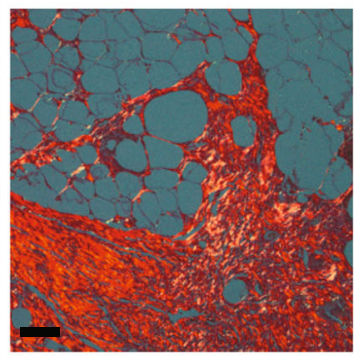

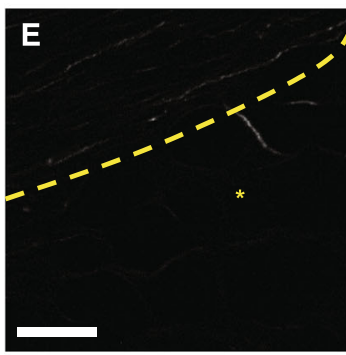

WT

$\mathbf{F}$
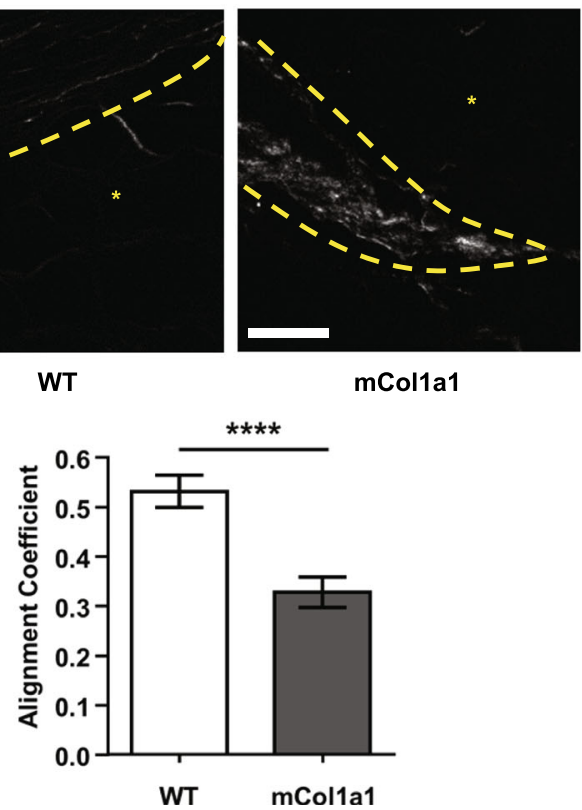

mCol1a1

WT

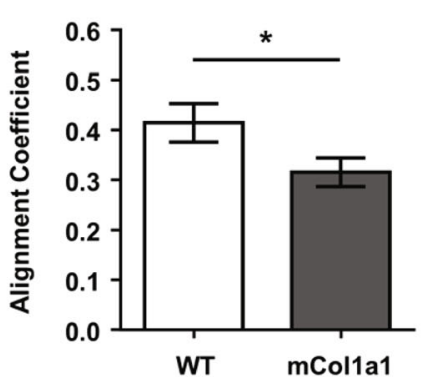

Fig. 5 (See legend on next page.) 
(See figure on previous page.)

Fig. 5 Early lesions in mCol1a1 recipients display invasive protrusions that contain aligned collagen fibers. a Hematoxylin/eosin stain (H\&E) of tumor cell line (TC)2 tumors (left panels) at 17 days, TC4 tumors (right panels) at 24 days after transplantation. b Tumor edges (H\&E). Arrowheads indicate finger-like protrusions into the mammary fat pad. $\mathbf{c}$ Higher magnification of boxed area from (b). $\mathbf{d}$ Picrosirius red staining. Note yellow-orange fibers in the protrusions in mCol1a1 tumors. Original magnification $\times 100 . \mathbf{a}, \mathbf{b}, \mathbf{d}$, scale bars $=100 \mu \mathrm{m}$. e Second harmonic generation (SHG) imaging of collagen fibers. Yellow dashed lines indicate tumor boundaries. *Indicates adjacent fat pad. Representative images $x$ 400 magnification. Scale bars $=50 \mu \mathrm{m}$. $\mathbf{f}$ CurveAlign analysis of relative collagen alignment following CT-FIRE fiber extraction as described in

"Methods". 0 = perfectly random fibers, $1=$ perfectly aligned fibers. Mean \pm SEM, $n=4$ tumors of each cell line/host genotype combination, 7-9 images per tumor. Repeated measures, group comparison, SAS Proc Mixed model. ${ }^{*} p<0.05,{ }^{* * *} p<0.001$. WT wild-type

induced $\mathrm{ER} \alpha+$ mammary carcinomas, driving local invasion of the primary tumor, realigning collagen fibers, mobilizing tumor epithelia, and enhancing pulmonary metastases. These data indicate that the ECM can alter hormonal signals to drive aggressive behavior of $\mathrm{ER} \alpha+\mathrm{tu}-$ mors, providing mechanistic insight into their metastasis.

Extensive in vitro studies of human breast cancer cells have shown that the PRLR, like other cytokine receptors, can activate multiple signaling pathways [17]. However, the determinants of the spectrum of signaling pathways, and their respective roles in disease in vivo have been unclear. In normal mammary development, PRL signals primarily through JAK2/STAT5 to direct expansion and differentiation of the mammary epithelia in concert with ovarian steroids $[49,50]$. Consistent with clinical data demonstrating that high STAT5 activation in breast cancers predicts favorable outcomes [19-21], constitutive activation of STAT5 in mouse models leads to welldifferentiated tumors [51]. Interestingly, signals through this pathway are required for initiation, but not progression, of PRL-induced cancers in NRL-PRL females [52]. However, many ER $\alpha$ + cancers that develop in this model are very aggressive, and display highly activated ERK1/2 and AKT [33, 38], indicating activation of non-JAK2/ STAT5 pathways. The data presented herein substantiate that the ECM is a potent determinant of the signaling cascades and outcomes of PRL actions in vivo, illuminating the apparent disparity between PRL exposure and activated STAT5 in the progression of clinical breast cancer. Moreover, our findings suggest that targeting non-canonical PRL signals may be of therapeutic benefit.

Mammographic density is a strong predictor of breast cancer risk [53-55]. However, epidemiologic data linking ECM density and breast cancer aggression are inconsistent $[56,57]$. Mammographically dense tissue partly comprises increased fibrillar collagen [58]. Although this can stiffen the ECM $[7,59]$, the properties of density and stiffness are not always linked. For example, at involution following weaning, the mammary ECM contains higher levels of collagen I, yet the ECM is less stiff than that in the nulliparous gland [60]. This suggests a fundamental difference in ECM architecture between physiologic states and cancer which deserves further study. Interestingly, we have observed that the ECM features - stiffness and collagen-I ligand density - exert distinct effects on PRL-initiated signals, using polyacrylamide hydrogels in vitro: elevated density reduces PRL phosphorylation of STAT5, whereas stiffness augments PRL signals to ERK1/2 [61]. The alterations in both signaling cascades elicited by reduced collagen I degradation and the increase in collagen fibers aligned with invasive projections of the tumor mass observed in the current in vivo study suggest that PRL-expressing ER $\alpha+$ cancer can directly or indirectly remodel dense collagen matrices to increase stiffness and alignment. Further, PRL itself may contribute to collagen density. PRL and mammographic density are epidemiologically linked $[62,63]$ and PRL enhances the expression of mammary ECM components such as Col1a1 [64], and Tnc [65], which promotes cancer cell invasion [66]. Taken together with the current data, these observations begin to outline a model where the characteristics of PRL and ECM work together to promote the invasion and metastasis of hormoneresponsive breast cancer.

Mouse models of ER $\alpha$ + breast cancer are limited, and few develop distant metastases [31, 32]. Although patientderived xenografts are proving useful in elucidating the behavior of some breast cancer subtypes in vivo, they require highly immunocompromised hosts $[67,68]$, a substantial limitation in light of the accumulating evidence on the importance of the immune response in tumor progression and metastasis [69]. Moreover, ER $\alpha+$ breast tumors have been difficult to grow in mice, preventing the widespread use of patient-derived xenografts for this subtype. Interestingly, mice genetically engineered to express human PRL appear to increase successful transplantations of human primary ER $\alpha+$ breast cancer [70]. Our syngeneic model allows examination of the behavior of ER $\alpha+$ mammary cancers, including metastasis, permitting us to demonstrate potent interactions between the features of the ECM and PRL that drive aggression in vivo.

\section{Conclusions}

Our studies demonstrate that a collagen-I-dense ECM can potently alter hormonal signals to drive the progression of $\mathrm{ER} \alpha+$ breast cancer, increasing intravasation and pulmonary metastases. Our data provide evidence that increased collagen-I can shift the pattern of activated 
signaling cascades in tumor epithelia away from the positive prognostic mediator STAT5 toward pathways that drive poorer outcomes, ERK $1 / 2$ and AKT. This is associated with invasive protrusions of the primary tumor that harbor collagen fibers angled perpendicularly to the tumor mass, a hallmark of aggressive ER $\alpha+$ tumors. This remodeling of the surrounding ECM in conjunction with the ability of PRL to increase the expression of mammary ECM components, suggests a feedforward loop by which PRL can drive the metastasis of $\mathrm{ER} \alpha+$ cancers.

\section{Additional files}

Additional file 1: Clonal GFP+ TC2GR12 (TC2) and TC4GR5 (TC4) cells are ERa+, PRLR+, and express the signal mediators, STAT5, AKT, and ERK1/2. A Wild-type FVB/N mammary epithelial cells (MECs), parental TC2 and TC4 (pTC2, pTC4), and GFP+ TC2 and TC4 RNA were analyzed by real-time PCR for expression of the rat prolactin $(r P r l)$ transgene expressed by NRL-PRL animals. MECs did not express the transgene as expected and transfection with GFP did not alter transgene expression. $1=\mathrm{MEC} ; 2$ = parental TC2; $3=$ TC2GR12 (GFP+TC2); $4=$ parental TC4; $5=$ TC4GR5 (GFP+ TC4). B TC2GR12 (TC2) and TC4GR5 (TC4) cells were grown on tissue culture plastic, serum starved overnight, and protein lysates assayed via immunoblotting with the indicated antibodies. (PDF $96 \mathrm{~kb}$ )

Additional file 2: Flow cytometry gating strategy to detect circulating tumor cells. A-C Cultured TC cell lines were trypsinzed, fixed in 2\% PFA, and analyzed via flow cytometry. Gates were set to include size of the cells (A), inclusion of APC auto-fluorescence (B), and selection of GFP+ cells (C). D-F Cleared blood samples were labelled with APC-conjugated CD31, CD45 to mark hematopoietic cells and analyzed following the gating strategy in A-C. Selection for tumor epithelial size (D), APC-negative cells (E), and GFP+ circulating tumor epithelial cells (F). Representative gating strategy shown. (PDF 377 kb)

Additional file 3: Conditions for immunohistochemical and immunofluorescence antibodies. (PDF 256 kb)

Additional file 4: The mCol1a1 environment does not alter tumor PRLR expression, and tumors express progesterone receptors in localized foci. A TC tumors lysates were probed for PRLR. No significant differences were observed between WT and mCol1a1 tumors. Mean \pm SEM TC2 tumors: WT $n=7$, mCol1a1 $n=6$; TC4 tumors: WT $n=7$, mCol1a1 $n=8$. (Mann-Whitney $U$ test, $p>0.05)$. B Progesterone receptor immunohistochemical analysis. Progesterone receptor is expressed in localized foci (upper panel). Positive staining of ductal epithelium (lower panel). Original magnifications $\times 200$. Scale bar $=50 \mu \mathrm{m}$. (PDF $333 \mathrm{~kb}$ )

Additional file 5: Surface lung nodules. Lungs from animals with no tumor cell transplants, and those from tumor bearing WT, and mCol1a1 animals. Arrows depict surface lung nodules observed under dissection microscopy. Representative images. Scale bar $=2$ mm. (PDF 434 kb)

Additional file 6: $\mathrm{mCol} 1 \mathrm{a} 1$ reduces pSTAT5, and elevates pERK1/2 and PAKT in TC4 tumors, shown by immunohistochemical analysis. Immunohistochemical analysis of pSTAT5 (A), pERK1/2 (B), and pAKT S473 (C) of TC4 tumors. Original magnification $\times 200$. Scale bar $=50 \mu \mathrm{m}$. (PDF $473 \mathrm{~kb}$ )

\section{Abbreviations}

ABC: avidin-biotin complex; APC: allophycocyanin mCol1a1: col1a $1^{\text {tmi } 1 \mathrm{Jae} /+}$; CTC: circulating tumor cells; ECM: extracellular matrix; ERK: extracellular regulated kinase; ERa: estrogen receptor alpha; FAK: focal adhesion kinase; FBS: fetal bovine serum; FOV: field of view; GFP: green fluorescent protein; JAK: Janus kinase; NRL: neu-related lipocalin; PBS: phosphate-buffered saline; PRL: prolactin; SFK: src family kinase; SHG: second harmonic generation; STAT: signal transducer and activator of transcription; TC: tumor cell line; WT: wildtype FVB/N mice

\section{Acknowledgements}

We would like to thank Dr Ruth Sullivan for helpful discussions on the collagen environment, Kyle Wegner for technical assistance with picrosirius red staining and image processing, Adib Keikhosravi for useful input on imaging and analysis, Dr Chad Vezina for helpful discussions on collagen imaging and providing immunofluorescent microscopy capabilities, Dr Joan Jorgensen for providing the eGFP antibody and Melanie Iverson for assistance with the immunohistochemical analysis.

\section{Funding}

This work was supported in part by NIH F31 CA177047 (CEB), R01 CA157675 (LAS), R01 CA179556 (LAS, PK) and the University of Wisconsin Carbone Cancer Center Support Grant P30 CA014520.

Availability of data and materials

All available datasets are presented herein

\section{Authors' contributions}

CEB and LAS conceived and designed the study, and drafted the manuscript. CEB performed the transplantations, circulating tumor cell analyses, examination of lung metastases, and analyses of signaling pathways. KAO participated in the animal studies and immunohistochemical analysis, and interpretation of the data and manuscript review. JLB, DER and NG isolated and characterized the tumor cell lines, and their responses to the collagen environment. CEB and YL analyzed the collagen structure by second harmonic generation microscopy. MY performed statistical analyses and assisted in the interpretation of the analysis of collagen alignment. PJK and KWE participated in the design of the study and data interpretation, and edited the manuscript. All authors read and approved the final manuscript.

\section{Competing interests}

The authors declare that they have no competing interests.

\section{Consent for publication}

Not applicable.

Ethics approval and consent to participate

All animal studies were approved by the University of Wisconsin-Madison Animal Care and Use Committee.

\section{Author details}

${ }^{1}$ Cellular and Molecular Biology Program, University of Wisconsin-Madison, Madison, WI, USA. ${ }^{2}$ Department of Comparative Biosciences, University of Wisconsin-Madison, Madison, WI, USA. ${ }^{3}$ Department of Cell and Regenerative Biology, University of Wisconsin-Madison, Madison, WI, USA. ${ }^{4}$ Department of Biostatistics \& Medical Informatics, University of WisconsinMadison, Madison, WI, USA. ${ }^{5}$ Laboratory for Optical and Computational Instrumentation, University of Wisconsin-Madison, Madison, WI, USA. ${ }^{6}$ University of Wisconsin Paul P. Carbone Comprehensive Cancer Center, University of Wisconsin-Madison, Wisconsin, USA.

Received: 9 June 2016 Accepted: 24 December 2016

Published online: 19 January 2017

\section{References}

1. Anderson WF, Katki HA, Rosenberg PS. Incidence of breast cancer in the United States: current and future trends. J Natl Cancer Inst. 2011;103:1397-402.

2. Voduc KD, Cheang MCU, Tyldesley S, Gelmon K, Nielsen TO, Kennecke H. Breast cancer subtypes and the risk of local and regional relapse. J Clin Oncol. 2010;28:1684-91.

3. Early Breast Cancer Trialists' Collaborative Group (EBCTCG). Effects of chemotherapy and hormonal therapy for early breast cancer on recurrence and 15-year survival: an overview of the randomised trials. Lancet. 2005;365:1687-717.

4. Walker R. The complexities of breast cancer desmoplasia. Breast Cancer Res. 2001;3:143-5

5. Butcher $D$, Alliston T, Weaver V. A tense situation: forcing tumour progression. Nat Rev Cancer. 2009;9:108-22. 
6. Keely P. Mechanisms by which the extracellular matrix and integrin signaling act to regulate the switch between tumor suppression and tumor promotion. J Mammary Gland Biol Neoplasia. 2011;16:205-19.

7. Acerbi I, Cassereau L, Dean I, Shi Q, Au A, Park C, Chen YY, Liphardt J, Hwang ES, Weaver VM. Human breast cancer invasion and aggression correlates with ECM stiffening and immune cell infiltration. Integr Biol. 2015;7:1120-34.

8. Paszek MJ, Zahir N, Johnson KR, Lakins JN, Rozenberg GI, Gefen A, ReinhartKing CA, Margulies SS, Dembo M, Boettiger D, Hammer DA, Weaver VM. Tensional homeostasis and the malignant phenotype. Cancer Cell. 2005;8:241-54

9. Wei SC, Fattet L, Tsai JH, Guo Y, Pai VH, Majeski HE, Chen AC, Sah RL, Taylor SS, Engler AJ, Yang J. Matrix stiffness drives epithelial-mesenchymal transition and tumour metastasis through a TWIST1-G3BP2 mechanotransduction pathway. Nat Cell Biol. 2015;17:678-88.

10. Levental KR, Yu HM, Kass L, Lakins JN, Egeblad M, Erler JT, Fong SFT, Csisza K, Giaccia A, Weninger W, Yamauchi M, Gasser DL, Weaver VM. Matrix crosslinking forces tumor progression by enhancing integrin signaling. Cell. 2009;139:891-906.

11. Mouw JK, Yui Y, Damiano L, Bainer RO, Lakins JN, Acerbi I, Ou G, Wijekoon AC, Levental KR, Gilbert PM, Hwang ES, Chen Y-Y, Weaver VM. Tissue mechanics modulate microRNA-dependent PTEN expression to regulate malignant progression. Nat Med. 2014;20:360-7.

12. Riching KM, Cox BL, Salick MR, Pehlke C, Riching AS, Ponik SM, Bass BR, Crone WC, Jiang Y, Weaver AM, Eliceiri KW, Keely PJ. 3D Collagen alignment limits protrusions to enhance breast cancer cell persistence. Biophys J. 2014;107:2546-58

13. Conklin MW, Eickhoff JC, Riching KM, Pehlke CA, Eliceiri KW, Provenzano PP, Friedl A, Keely PJ. Aligned collagen is a prognostic signature for survival in human breast carcinoma. Am J Pathol. 2011;178:1221-32.

14. Provenzano PP, Inman DR, Eliceiri KW, Keely PJ. Matrix density-induced mechanoregulation of breast cell phenotype, signaling and gene expression through a FAK-ERK linkage. Oncogene. 2009:28:4326-43.

15. Damiano JS, Wasserman E. Molecular pathways: blockade of the PRLR signaling pathway as a novel antihormonal approach for the treatment of breast and prostate cancer. Clin Cancer Res. 2013;19:1644-50.

16. Fernandez I, Touraine P, Goffin V. Prolactin and human tumourogenesis. J Neuroendocr. 2010;22:771-7.

17. Clevenger CV, Furth PA, Hankinson SE, Schuler LA. The role of prolactin in mammary carcinoma. Endocr Rev. 2003;24:1-27.

18. Tworoger SS, Hankinson SE. Prolactin and breast cancer etiology: an epidemiologic perspective. J Mammary Gland Biol Neoplasia. 2008;13:41-53.

19. Yamashita H, Nishio M, Ando Y, Zhang Z, Hamaguchi M, Mita K, Kobayashi S, Fujii Y, Iwase H. Stat5 expression predicts response to endocrine therapy and improves survival in estrogen receptor-positive breast cancer. Endocr Relat Cancer. 2006;13:885-93.

20. Peck AR, Witkiewicz AK, Liu C, Stringer GA, Klimowicz AC, Pequignot E, Freydin B, Tran $\mathrm{TH}$, Yang N, Rosenberg AL, Hooke JA, Kovatich AJ, Nevalainen MT, Shriver CD, Hyslop T, Sauter G, Rimm DL, Magliocco AM, Rui H. Loss of nuclear localized and tyrosine phosphorylated Stat5 in breast cancer predicts poor clinical outcome and increased risk of antiestrogen therapy failure. J Clin Oncol. 2011;29:2448-58.

21. Cotarla I, Ren S, Zhang Y, Gehan E, Singh B, Furth PA. Stat5a is tyrosine phosphorylated and nuclear localized in a high proportion of human breast cancers. Int J Cancer. 2004;108:665-71.

22. Sultan AS, Xie J, LeBaron MJ, Ealley EL, Nevalainen MT, Rui H. Stat5 promotes homotypic adhesion and inhibits invasive characteristics of human breast cancer cells. Oncogene. 2005;24:746-60.

23. Nouhi Z, Chughtai N, Hartley S, Cocolakis E, Lebrun J-J, Ali S. Defining the role of prolactin as an invasion suppressor hormone in breast cancer cells. Cancer Res. 2006:66:1824-32.

24. Acosta JJ, Muñoz RM, González L, Subtil-Rodríguez A, Dominguez-Caceres MA, García-Martínez JM, Calcabrini A, Lazaro-Trueba I, Martín-Pérez J. Src mediates prolactin-dependent proliferation of T47D and MCF7 cells via the activation of focal adhesion kinase/Erk1/2 and phosphatidylinositol 3-kinase pathways. Mol Endocrinol. 2003;17:2268-82.

25. Canbay E, Norman M, Kilic E, Goffin V, Zachary I. Prolactin stimulates the JAK2 and focal adhesion kinase pathways in human breast carcinoma T47-D cells. Biochem J. 1997:324:231-6.

26. Piazza TM, Lu JC, Carver KC, Schuler LA. Src family kinases accelerate prolactin receptor internalization, modulating trafficking and signaling in breast cancer cells. Mol Endocrinol. 2009;23:202-12.
27. Gutzman JH, Rugowski DE, Nikolai SE, Schuler LA. Stat5 activation inhibits prolactin-induced AP-1 activity: distinct prolactin-initiated signals in tumorigenesis dependent on cell context. Oncogene. 2007;26:6341-8.

28. Barcus CE, Keely PJ, Eliceiri KW, Schuler LA. Stiff collagen matrices increase tumorigenic prolactin signaling in breast cancer cells. J Biol Chem. 2013;288:12722-32

29. Barcus CE, Holt EC, Keely PJ, Eliceiri KW, Schuler LA. Dense collagen-I matrices enhance pro-tumorigenic estrogen-prolactin crosstalk in MCF-7 and T47D breast cancer cells. PLoS One. 2015;10, e0116891.

30. Bonnans C, Chou J, Werb Z. Remodelling the extracellular matrix in development and disease. Nat Rev Mol Cell Biol. 2014;15:786-801.

31. Mohibi S, Mirza S, Band H, Band V. Mouse models of estrogen receptorpositive breast cancer. J Carcinog. 2011;10:35.

32. Dabydeen SA, Furth PA. Genetically engineered ER alpha positive breast cancer mouse models. Endocr Relat Cancer. 2014;21:R195-208.

33. O'Leary KA, Shea MP, Schuler LA. Modeling prolactin actions in breast cancer in vivo: insights from the NRL-PRL mouse. Adv Exp Med Biol. 2015;846:201-20.

34. Brockman J, Arendt L, Rugowski D, Schuler L. Mammary tumor cell lines developed from transgenic prolactin-induced mammary tumors retain dependence on prolactin for growth. 88th Annu Meet Endocr Soc Boston, MA. 2006:P2-296

35. Liu X, Wu H, Byrne M, Jeffrey J, Krane $S$, Jaenisch R. A targeted mutation at the known collagenase cleavage site in mouse type I collagen impairs tissue remodeling. J Cell Biol. 1995;130:227-37.

36. Provenzano PP, Inman DR, Eliceiri KW, Knittel JG, Yan L, Rueden CT, White JG, Keely PJ. Collagen density promotes mammary tumor initiation and progression. BMC Med. 2008;6:15.

37. Rose-Hellekant TA, Arendt LM, Schroeder MD, Gilchrist K, Sandgren EP, Schuler LA. Prolactin induces ER[alpha]-positive and ER[alpha]-negative mammary cancer in transgenic mice. Oncogene. 2003;22:4664-74.

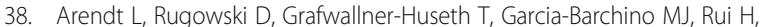
Schuler L. Prolactin-induced mouse mammary carcinomas model estrogen resistant luminal breast cancer. Breast Cancer Res. 2011:13:R11.

39. Schneider CA, Rasband WS, Eliceiri KW. NIH Image to ImageJ: 25 years of image analysis. Nat Methods. 2012;9:671-5.

40. Bauman TM, Nicholson TM, Abler LL, Eliceiri KW, Huang W, Vezina CM, Ricke WA. Characterization of fibrillar collagens and extracellular matrix of glandular benign prostatic hyperplasia nodules. PLoS One. 2014;9, e109102.

41. Provenzano PP, Eliceiri KW, Yan L, Ada-Nguema A, Conklin MW, Inman DR, Keely PJ. Nonlinear optical imaging of cellular processes in breast cancer. Microsc Microanal. 2008;14:532-48.

42. Bredfeldt JS, Liu Y, Pehlke CA, Conklin MW, Szulczewski JM, Inman DR, Keely PJ, Nowak RD, Mackie TR, Eliceiri KW. Computational segmentation of collagen fibers from second-harmonic generation images of breast cancer. $J$ Biomed Opt. 2014;19:16007.

43. Bredfeldt JS, Liu Y, Conklin MW, Keely PJ, Mackie TR, Eliceiri KW. Automated quantification of aligned collagen for human breast carcinoma prognosis. J Pathol Inform. 2014:5:28

44. Weigelt B, Peterse $J L$, van't Veer $L J$. Breast cancer metastasis: markers and models. Nat Rev Cancer. 2005;5:591-602.

45. McCubrey JA, Steelman LS, Abrams SL, Lee JT, Chang F, Bertrand FE, Navolanic PM, Terrian DM, Franklin RA, D'Assoro AB, Salisbury JL, Mazzarino MC, Stivala F, Libra M. Roles of the RAF/MEK/ERK and PI3K/PTEN/AKT pathways in malignant transformation and drug resistance. Adv Enzyme Regul. 2006:46:249-79.

46. $\mathrm{Ma}$ CX. The PI3K pathway as a therapeutic target in breast cancer. Am J Hematol/Oncol. 2015;11:23-9.

47. Johnston SRD. Enhancing endocrine therapy for hormone receptor-positive advanced breast cancer: cotargeting signaling pathways. J Natl Cancer Inst. 2015;107:djv212

48. Provenzano PP, Eliceiri KW, Campbell JM, Inman DR, White JG, Keely PJ. Collagen reorganization at the tumor-stromal interface facilitates local invasion. BMC Med. 2006:4:38.

49. Hennighausen L, Robinson GW, Wagner KU, Liu X. Developing a mammary gland is a stat affair. J Mammary Gland Biol Neoplasia. 1997;2:365-72.

50. Oakes SR, Rogers RL, Naylor MJ, Ormandy CJ. Prolactin regulation of mammary gland development. J Mammary Gland Biol Neoplasia. 2008;13:13-28

51. lavnilovitch E, Groner B, Barash I. Overexpression and forced activation of stat5 in mammary gland of transgenic mice promotes cellular proliferation, 
enhances differentiation, and delays postlactational apoptosis. Mol Cancer Res. 2002;1:32-47.

52. Sakamoto K, Triplett AA, Schuler LA, Wagner K-U. Janus kinase 2 is required for the initiation but not maintenance of prolactin-induced mammary cancer. Oncogene. 2010;29:5359-69.

53. Vachon CM, van Gils CH, Sellers TA, Ghosh K, Pruthi S, Brandt KR, Pankratz VS. Mammographic density, breast cancer risk and risk prediction. Breast Cancer Res. 2007;9:217.

54. Boyd NF, Martin L, Bronskill M, Yaffe MJ, Duric N, Minkin S. Breast tissue composition and susceptibility to breast cancer. J Natl Cancer Inst. 2010;102:1224-37.

55. Sherratt MJ, McConnell JC, Streuli CH. Raised mammographic density: causative mechanisms and biological consequences. Breast Cancer Res. 2016;18:45.

56. Maskarinec G, Pagano IS, Little MA, Conroy SM, Park S-Y, Kolonel LN. Mammographic density as a predictor of breast cancer survival: the Multiethnic Cohort. Breast Cancer Res. 2013;15:R7.

57. Gierach GL, Ichikawa L, Kerlikowske K, Brinton LA, Farhat GN, Vacek PM, Weaver DL, Schairer C, Taplin SH, Sherman ME. Relationship between mammographic density and breast cancer death in the Breast Cancer Surveillance Consortium. J Natl Cancer Inst. 2012;104:1218-27.

58. Li T, Sun LM, Miller N, Nicklee T, Woo J, Hulse-Smith L, Tsao M-SS, Khokha R, Martin L, Boyd N. The association of measured breast tissue characteristics with mammographic density and other risk factors for breast cancer. Cancer Epidemiol Biomarkers Prev. 2005;14:343-9.

59. Boyd NF, Li Q, Melnichouk O, Huszti E, Martin L, Gunasekara A, Mawdsley $\mathrm{G}$, Yaffe MJ, Minkin S. Evidence that breast tissue stiffness is associated with risk of breast cancer. PLoS One. 2014;9, e100937.

60. Maller O, Hansen KC, Lyons TR, Acerbi I, Weaver VM, Prekeris R, Tan A-C, Schedin P. Collagen architecture in pregnancy-induced protection from breast cancer. J Cell Sci. 2013;126(Pt 18):4108-10.

61. Barcus CE, Keely PJ, Eliceiri KW, Schuler LA. Prolactin signaling through focal adhesion complexes is amplified by stiff extracellular matrices in breast cancer cells. Oncotarget. 2016;7:48093-106.

62. Boyd NF, Stone J, Martin LJ, Jong R, Fishel E, Yaffe M, Hammond G, Minkin $\mathrm{S}$. The association of breast mitogens with mammographic densities. $\mathrm{Br} \mathrm{J}$ Cancer. 2002:87:876-82.

63. Greendale GA, Huang M-HH, Ursin G, Ingles S, Stanczyk F, Crandall C, Laughlin GA, Barrett-Connor E, Karlamangla A. Serum prolactin levels are positively associated with mammographic density in postmenopausal women. Breast Cancer Res Treat. 2007;105:337-46.

64. Gass S, Harris J, Ormandy C, Brisken C. Using gene expression arrays to elucidate transcriptional profiles underlying prolactin function. J Mammary Gland Biol Neoplasia. 2003:8:269-85.

65. Arendt LM, Evans LC, Rugowski DE, Garcia-Barchino MJ, Rui H, Schuler LA. Ovarian hormones are not required for PRL-induced mammary tumorigenesis, but estrogen enhances neoplastic processes. J Endocrinol. 2009;203:99-110.

66. Hancox RA, Allen MD, Holliday DL, Edwards DR, Pennington CJ, Guttery DS, Shaw JA, Walker RA, Pringle JH, Jones JL. Tumour-associated tenascin-C isoforms promote breast cancer cell invasion and growth by matrix metalloproteinase-dependent and independent mechanisms. Breast Cancer Res. 2009;1 1:R24

67. Tentler JJ, Tan AC, Weekes CD, Jimeno A, Leong S, Pitts TM, Arcaroli JJ, Messersmith WA, Eckhardt SG. Patient-derived tumour xenografts as models for oncology drug development. Nat Rev Clin Oncol. 2012;9:338-50.

68. Whittle JR, Lewis MT, Lindeman GJ, Visvader JE. Patient-derived xenograft models of breast cancer and their predictive power. Breast Cancer Res. 2015;17:17.

69. Jiang $X$, Shapiro DJ. The immune system and inflammation in breast cancer. Mol Cell Endocrinol. 2014:382:673-82.

70. Rui H, Utama FE, Yanac AF, Xia G, Peck AR, Liu C, Rosenberg AL, Wagner KU, Yang N. Abstract S1-8: Prolactin-humanized mice: an improved animal recipient for therapy response-testing of patient-derived breast cancer xenotransplants. Cancer Res. 2012;72(24 Supplement):S1-8.

\section{Submit your next manuscript to BioMed Central and we will help you at every step:}

- We accept pre-submission inquiries

- Our selector tool helps you to find the most relevant journal

- We provide round the clock customer support

- Convenient online submission

- Thorough peer review

- Inclusion in PubMed and all major indexing services

- Maximum visibility for your research

Submit your manuscript at www.biomedcentral.com/submit
) Biomed Central 